\title{
A Novel of Data Gathering Method for User Activity Characterisation in an Office Environment to Improve Energy Efficiency
}

\author{
Saifullizam Puteh ${ }^{1}$, Ahmad Lotfi $^{2}$, Caroline Langensiepen ${ }^{3}$, S. C. Johnson Lim ${ }^{4}$, Rosnawati Buhari ${ }^{5}$ \\ ${ }^{1,4}$ Faculty of Technical and Vocational Education, Universiti Tun Hussein Onn Malaysia \\ ${ }^{2,3}$ Faculty of Science and Technology, Nottingham Trentt University, United Kingdom \\ ${ }^{5}$ Faculty of Civil and Environmental Engineering, Universiti Tun Hussein Onn Malaysia
}

\begin{abstract}
The research aim is to investigate different methods of profiling user activities in an office environment. This will allow optimal use of resources in future Intelligent Office Environments while still taking account of user preferences and comfort. To achieve the goal of this research, a data collection system is designed and built. This required a wireless Sensor Network to monitor a wide range of ambient conditions and user activities, and a software agent to monitor user's Personal Computer activities. Collected data from different users are gathered into a central database and converted into a meaningful format for description of the worker's Activity of Daily Working (ADW) and office environment conditions. Statistical techniques are employed to quantify a user's behaviour and extract a user profile. The individual user profile is representative of a user's preferences, consisting of user routine activities, consistency of office usage and their thermal comfort. Using the statistical it is possible to characterise different users with only a few parameters. This helps to assess the importance of those aspects within the profile. The novel contribution is the use of these techniques within the context of ADW.
\end{abstract}

Keywords: intelligent office environment, building management system, wireless sensor network, human activity recognition

\section{Introduction}

Office workers' performance and comfort in an office environment can depend on temperature, ventilation and lighting. Their power usage depends on the way they have adjusted their environment to optimise these characteristics, together with their usage of their Personal Computer (PC) [1]. We must therefore consider the way in which one could monitor these characteristics (of both the worker and their environment) in order to log the data. The data capture and logging must be as unobtrusive as possible in order to avoid affecting the behaviour of the worker, and should not increase their stress.

Pervasive sensing technologies in intelligent environments offer unprecedented opportunities for providing intelligent office monitoring and self-management to change office conditions that are directly suited to user satisfaction levels [2],[3] dan [4]. As part of our investigation to understand an office worker's behaviours and ultimately optimise the energy usage, a monitoring system is required. The proposed experimental system architecture is explained in this paper. Investigated techniques in data collection system are also presented in this paper.

The remaining parts of this paper are organised as follows; in Section 2 an overview of the proposed system architecture is presented. In Section 3, real data collection system is explained. In the Section 4 an overview of the activity characterization of a user in an office environment is described. Some experimental results are presented in Section 5. Section 6 draws some conclusions.

\section{Proposed System Architecture}

+ Corresponding author. Tel.: + 6074564119; fax: +6074536585

E-mail address: saifull@uthm.edu.my 
We may classify the needs of our experimental system for an office as the ability to detect occupancy, record the ambient conditions (and any worker responses to them), and to identify activities. Occupancy detection may be considered to be covered by Passive Infra-Red (PIR) motion sensors and door entry sensors. PIR motion sensors are low cost and readily available, though their typical activity thresholds mean that a worker quietly reading or writing a document would not cause them to signal. Door entry sensors are relatively unambiguous. However, a visitor to an office would also trigger the open-shut sequence, so the office occupancy could not necessarily be deduced simply from the door. Thus occupancy needs to be deduced from a combination of these signals together with additional information provided by other sensors. The ambient conditions can be recorded via temperature sensors (inside the office and outside the building) and light sensors. It is possible to identify when a person is actually typing at a PC, or moving a mouse, by adding a background software agent. If a worker is at a desk reading a report, the PC activity might halt for a considerable time, and the PIR might not trigger. An additional Boolean signal generated by a pressure sensor in the worker's seat could indicate when they are at their desk.

The proposed system architecture to measure office worker's activities and energy usage is shown in Fig. 1. The proposed system comprises the following data collection components:

- sensors to measure user's activities and environmental properties,

- communication system to transfer collected data into a central database,

- PC monitoring application agent,

- a central database to store collected data.

The proposed system has also incorporated:

- behaviour identification and user profiling,

- computer usage, lighting and heating controller.

More details about the functionality of the above units will be provided in subsequent sections.

\subsection{Sensors}

The ambient conditions are recorded via temperature, humidity and light sensors (inside the office and external to the building). The responses of the office worker are also captured via his/her activities in the office environment.

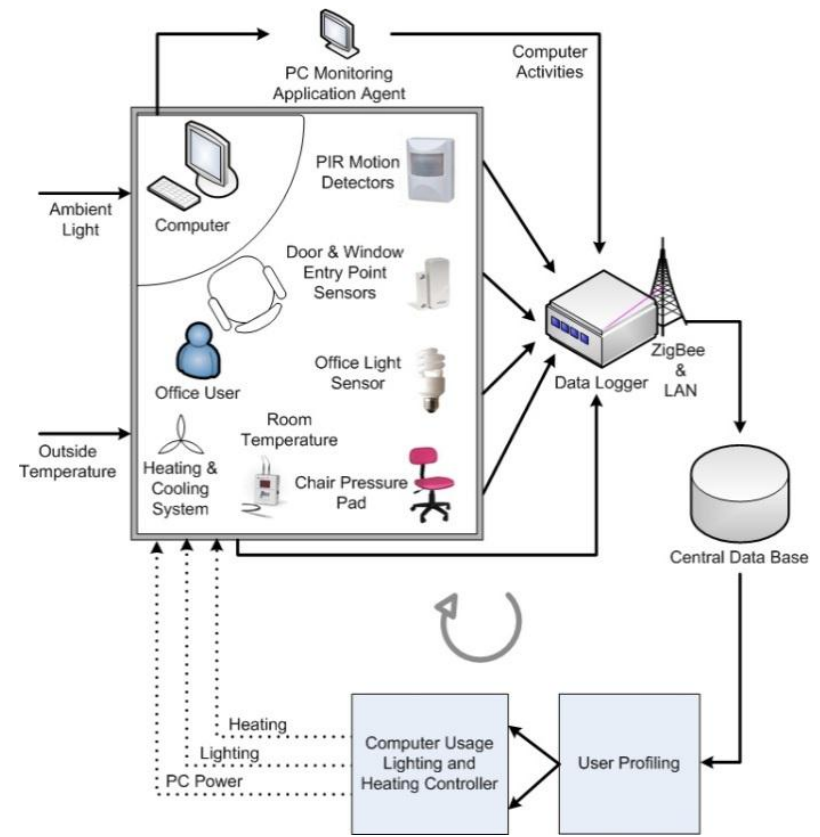

Fig. 1. Proposed system architecture for intelligent office environment.

The most commonly used sensor types in smart environment are as follows [5]:

- PIR Sensor: PIR sensor is activated when detecting movement.

- Magnetic switch sensor: This sensor is suitable for door/windows entry. A magnetic field make the switch changes state from opened to closed and vice versa. 
- Temperature sensor: There are a variety of sensors to measure the ambient temperature. For example, DB18B20 is a solid-state sensor commonly used to measure the environmental temperature. It operates in the range of temperature $-55{ }^{\circ} \mathrm{C}$ to $125{ }^{\circ} \mathrm{C}$ and can be powered from a data line with a range of $3.0 \mathrm{~V}$ to $5.5 \mathrm{~V}$.

- Humidity sensor: Humidity sensors, otherwise known as hygrometers, measure the relative humidity of the air. This is based on both air temperature and moisture. This dependency is a function of air temperature fluctuations. For example, the humidity sensor $\mathrm{HIH}-4000-001$ is a solid-state sensing element with on-chip integrated signal conditioning. It is calibrated at $5 \mathrm{~V}$ and $25^{\circ} \mathrm{C}$.

- Light intensity sensor: The light intensity sensor is also known as a photoresistor which has the property of reducing resistance with increase in light intensity, allowing an increase in flow of photo-current.

- Electrical current sensor: A non-contact sensor is used to record the activity of electrically operated devices by measuring AC electrical current, and

- Pressure pad sensor: This type of sensor is mounted on chair to be able to pick the difference in the pressure on the chair.

\subsection{Communication System}

In order to make the data collection system more flexible and less intrusive, a Wireless Sensor Network (WSN) is developed. The developed WSN is based on ZigBee wireless technology. The ZigBee network is proven to be a suitable technology for our application mainly because it is a low date rate, low power consumption and low cost wireless standard.

ZigBee is a wireless networking technology developed by the ZigBee Alliance for low data rate and short range application. According to IEEE 802.15.4 standard, the full function device can work as ZigBee coordinator or router in Zig- Bee network and operates in $868 \mathrm{MHz}, 915 \mathrm{MHz}$ and $2.4 \mathrm{GHz}$ bands. These frequency signal bands are available in Europe, North America and worldwide respectively [6]. The application of ZigBee wireless network in many industrial control, electronic product and house automation are reported in [7] [8] and [9].

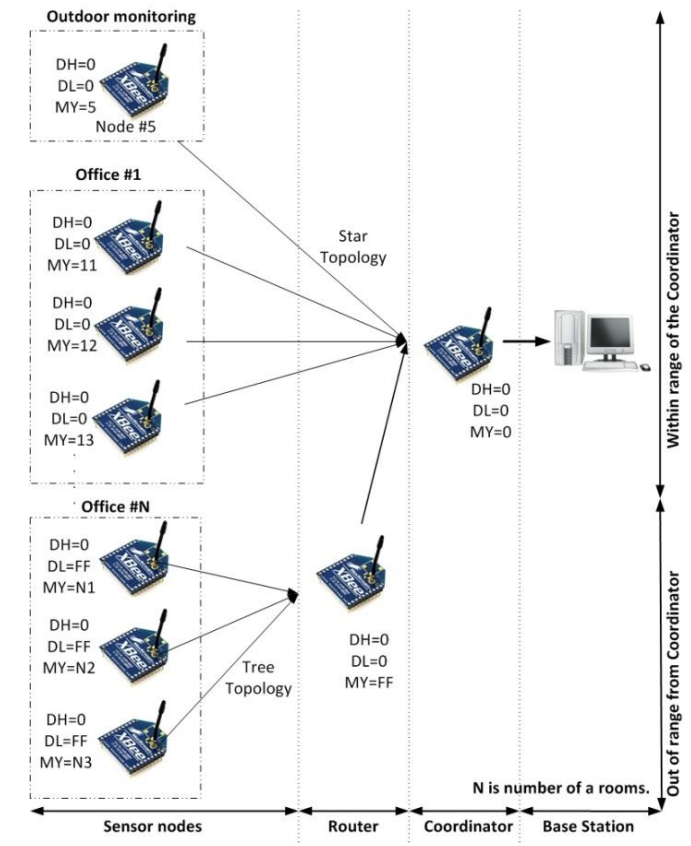

Fig. 2. Propose system architecture for intelligent office environment.

To develop a WSN to collect information from various sensors, the network is developed using XBee modules. XBee [10] is a wireless communication module that Digi(http://www.digi.com) built to the 802.15.4/ZigBee standard. Each node used PICAXE-18X micro-controller to program the node functionalities. 
The ZigBee wireless sensor network is designed based on both Star and Tree network topologies which includes sensor node, router and coordinator nodes. If one office is more than 20 meter away from the coordinator node, a router is used to extent the physical range of a ZigBee network. The coordinator node is responsible for network address allocation, to collect data sent from sensor nodes and communicating with PC in base station through a serial port. Fig. 2 illustrates the overall structure of the proposed wireless sensor network.

The important part of the monitoring application has to detect when mouse or keyboard events happen. After being able to detect keyboard and mouse events to indicate they are in use, it needs to be determined when the keyboard and mouse are no longer in use. The best way to do this would be to have a time period where if no mouse or keyboard events have been detected then they are deemed to be no longer in use. Activating a timer after detecting the mouse or keyboard is in use would make this possible. It would have to be possible to reset the timer though as if any mouse or keyboard events are detected while they stated to be in use then the time range to deeming not in use needs to be restarted. This would mean that if the main application is doing a task then the timer would be stopped until that task is completed and vice versa. The PC monitoring application needs to communicate with the control server application in both directions. It needs to send a message to the control server application when the PC has gone idle or change state, informing the control server application that the PC's state has changed.

\subsection{Database}

A database records events triggered by the PC software agents and WSN. The database logs individual events for any further analysis. In the database design, the database contains tables for device usage events, PC MAC address, PC statuses and sensor statuses. The following tables are used for managing storing data in the database system:

- Device Usage Events

- PC MAC Address

- PC Statuses

- Sensor Status

The Device Usage Events table has a many to one relationship to Sensor Statuses table and PC Status table. The PC Status table has a many to one relationship to PC MAC Address table. Sensor Status table has one to many relationship with Device Usage Events, which also have many to one relationship to PC MAC Address.

\section{Data Collection}

The office environments used as the testbed for our experiment are four academic staff offices at Computing and Informatics Building, Nottingham Trent University. Collected data from offices include room status, power use of office equipment and ambient information.

In total, each office is equipped with 10 sensors measuring different activities and properties of the testbed environment. The sensors include:

- Motion sensor (On/Off)

- Door entry point sensor (On/Off)

- Windows entry point sensor (On/Off)

- Pressure sensor measuring chair occupancy (On/Off)

- Room temperature

- Room humidity

- Outside temperature

- Room light intensity

- Ambient light intensity

- Radiator Heater Temperature

These sensors provide information regarding the occupancy and ambient conditions. 
Office door activities, room occupancy status, light activities, chair occupancy status, computer activities, window open/close status, radiator temperature, room temperature, room humidity, outdoor temperature and ambient lights are recorded.

\section{Results}

Time-series signals of user activities and ambient conditions in an office environment are recorded using a data collection system. The sensor output for door, PIR, chair and window are represented in binary format. Therefore it is possible to combine all and represent all these binary sequences in one sequence with real values. To achieve this, the binary bit representing the state of a signal at any instance is merged together to generate an $n$ bits binary code where $n$ represents the number of signals. For example, using start-time and duration form of representation, in Fig. 3 shows door activities over 5 working days are illustrated for User \#1. However, these signals provided little information to detect behaviour; and thus construct a user profile.

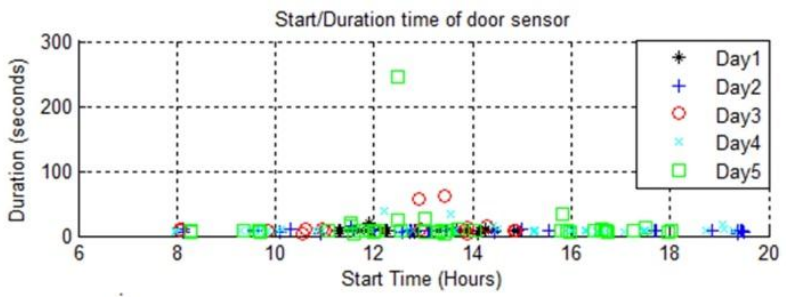

Fig. 3. The door activities over five working days for User \#1
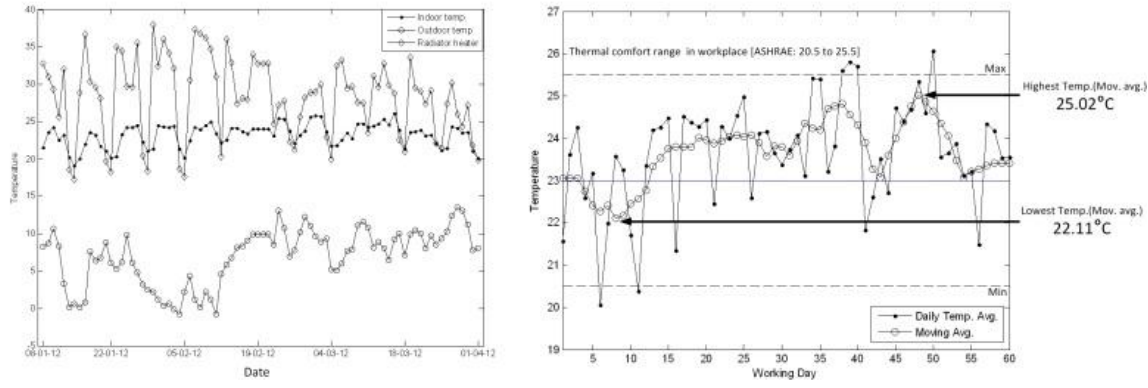

Fig. 4. The office temperature readings for User \#2

To assess the thermal comfort in the office environment, ambient room temperature, outside temperature and radiator temperatures are measured. It is expected that these measurements will provide us with the thermal comfort range. Fig. 4 shows the heating temperature from radiator heater in an office is significant due to the low temperature of outdoor temperature for User \#2. Since a radiator heater is ON, it will change the indoor thermal comfort. The arrow lines are used to locate points on maximum and minimum values of temperature moving average to define the thermal comfort range of user's office. The moving average is computed by averaging with five data points as five working days (Monday to Friday) in a week of data over sixty days. Statistical analysis experiments in this study detected that each office user had different behaviours. The ADW of office workers had different patterns on different days of the week.

TAB. 1. USER PROFILES, USED FOR SUMMARIZING USER'S BEHAVIOR IN AN OFFICE ENVIRONMENT OVER TWELVE WEEKS

\begin{tabular}{ccccccc}
\hline User & Working Time & Avg. Duration/Routine habit of activity in an office & $\begin{array}{c}\text { Thermal } \\
\text { Comfort }\end{array}$ \\
\hline & & & &
\end{tabular}


TAB. 2. FORMULAS USED TO EXTRACT PROFILE INFORMATION FROM THE USER'S BEHAVIOR

\begin{tabular}{|c|c|c|c|c|}
\hline $\begin{array}{l}\text { Working } \\
\text { Time }\end{array}$ & \multicolumn{3}{|c|}{ Duration / Routine habit of activity in an office } & $\begin{array}{l}\text { Thermal } \\
\text { Comfort }\end{array}$ \\
\hline Arr. $=\min \left(t_{\text {door }}\right)$ & $\begin{array}{l}\text { Avg. Duration } \\
L>25_{\underline{\text { hours }}}\end{array}$ & $\begin{array}{c}\text { Consistency } \\
\alpha\end{array}$ & $\begin{array}{l}\text { Chaotic } \\
\text { ApEn }\end{array}$ & $\begin{array}{c}\text { Temperature } \\
\min (t m p) \text { to } \max (t m p)\end{array}$ \\
\hline Dept. $=\max \left(t_{\text {door }}\right)$ & $\begin{aligned} 15_{\frac{\text { hours }}{\text { week }}} & <M<25_{\frac{\text { hours }}{\text { week }}}^{\text {week }} \\
0_{\frac{\text { hours }}{\text { week }}} & <S<15_{\frac{\text { hours }}{\text { week }}}\end{aligned}$ & $\begin{array}{c}C: \alpha>0.5 \\
\text { In } C: \alpha<0.5\end{array}$ & $\begin{array}{c}P: A p E n<0.6 \\
U n P: A p E n>0.6\end{array}$ & $\begin{array}{c}t m p=\text { Tmp. for moving } \\
\text { avg. of } 5 \text { data points }\end{array}$ \\
\hline
\end{tabular}

For example, the results shown in Table I indicate that User \#1, \#2, \#4 are dissimilar habitually at the start of work, where User \#1 is the earliest to arrive at the office, and User \#2 left the office for the day later than other users. In terms of user activity duration, due to different schedules of work, User \#2 spent more time in the office with above average computer usage than User \#1 and \#4. Based on the consistency and chaotic measures [11] of user's activity, we found that the consistency of computer activity for User \#1 is inconsistent with the other users, with an $\alpha$ of less than 0.5 , and the chaotic levels of all activities of user's is moderate, with an Approximate Entropy Measure (ApEn) [12] of less than 0.8. According to the results, each office user's working attitude and preferences could be summarised in the profile properties (as shown in Tab. 1). Tab. 2 shows the formulas used to extract users' profile information from the users' behaviour data.

\section{Conclusions}

Several experiments in this paper are successfully implemented, and methods used to analyse data from office worker's behavior in an office environment are proposed. In order to deal with large ADW binary signals, several progressive methods of data representation and converting sensory signals into multidimensional knowledge are proposed. Converting data into start-time and duration sequences, and signal unification.

In conclusion, the individual user's profile (as shown in Tab. 1) can be used to distinguish between different user's profiles. Moreover, repetitive regular behaviour patterns can be detected using the similarity algorithms. This would benefit an office environment control system, by enabling it to recognise real users and update the user's profile. This would also enable the office environment to be automatically adjusted in line with the user's preferences. The control system could be improved; if it is able to identify the similarities and changes of user's behaviour over a period of time.

\section{Acknowledgements}

The authors wish to thank Universiti Tun Hussein Onn Malaysia and Nottingham Trent University, United Kingdom. This paper is partially sponsored by a research grant by Ministry of Higher Education Malaysia (MDR U098)

\section{References}

[1] C. Langensiepen, A. Lotfi and S. Puteh, "Activities recognition and worker profiling in the intelligent office environment using a fuzzy finite state machine," 2014 IEEE International Conference on Fuzzy Systems (FUZZ-IEEE), Beijing, 2014, pp. 873-880. doi: 10.1109/FUZZ-IEEE.2014.6891825

[2] Saifullizam Puteh, Caroline Langensiepen, and Ahmad Lotfi, "Similarity pattern mining in intelligent office environments", in Workshop Proceedings of the 7th International Conference on Intelligent Environments, vol. 10, pp. 562-573, 2011.

[3] S. Puteh, C. Langensiepen, and A. Lotfi, "Fuzzy ambient intelligence for intelligent office environments", in Fuzzy Systems (FUZZ-IEEE), 2012 IEEE International Conference on, 2012, pp. 1-6

[4] Saifullizam Puteh, Caroline Langensiepen, and Ahmad Lotfi, "University office simulator for energy and comfort optimisatio", the 25th European Conference on Modelling and Simulation (ECMS 2011), pp. 430-435, 2011

[5] Javad M. Akhlaghinia, "Occupancy monitoring and prediction in ambient intelligent environment", $\mathrm{PhD}$ Thesis, School of Science and Technology, Nottingham Trent University, 2010. 
[6] C. Gomez and J. Paradells, "Wireless home automation networks: A survey of architectures and technologies", Communications Magazine, IEEE, vol. 48, no. 6, pp. 92-101, 2010.

[7] Yaning Wang and Zhaofeng Wang, "Design of intelligent residential lighting control system based on zigbee wireless sensor network and fuzzy controller", in Machine Vision and Human-Machine Interface (MVHI), 2010 International Conference on, 2010, pp. 56-564.

[8] J. Ohtsuka, T. Isokawa, A. Saitoh, N. Kamiura, N. Matsui, H. Kawa, and S. Nakashima, "Implementing localization scheme on zigbee wireless sensor network", in SICE Annual Conference 2010, Proceedings of, 2010, pp. 1195-1199.

[9] Matlab and Simulink, "Stateflow 7 user`s guide", The MathWorks, Inc., 2010.

[10] Martin Hebel, George Bricker, and Daniel Harris, "Getting Started with XBee RF Modules - A Tutorial for BASIC Stamp and Propeller Microcontrollers", PARALLAX Inc.

[11] Kilem Li Gwet, "Handbook of inter-rater reliability". 3nd ed., Advanced Analytics, LLC; USA, Advanced Analytics, LLC, P.O. Box 2696,Gaithersburg, MD 20886-2696,USA, 2012.

[12] S. M. Pincus, "Approximate entropy as measure of system complexity", Poceedings of the National Academy of Sciences of the United States of America, vol. 88, no. 6, pp. 2297-2301, 1991 